\title{
Influence of Institutional and Geographical Factors on the Openness and Dispersion of Knowledge- Sourcing Practices
}

Marcelo Cano-Kollmann

Ph.D. awarded by Temple University, USA (July 2015)

\section{BIG Question:}

"How do firms adapt their innovation activities to the constraints imposed by the location and the institutional environment in which they operate?"

\section{Introduction}

Organizations do not operate in a vacuum. They are embedded in specific geographic locations and are subject to institutional frameworks that constrain and shape the way they conduct business (CanoKollmann, Cantwell, Hannigan, Mudambi, \& Song, 2016). While this per se is not news, a perspective that incorporates both institutional and geographical factors still offers ample room to explore uncharted research questions. Furthermore, those questions hold big implications not only for academics but also for an array of stakeholders, from managers to policymakers.

It would be impossible to incorporate all, or even the majority, of those questions into one dissertation. I chose, instead, to explore three specific questions within this broader perspective, and simply point out that these areas are fertile ground for novel research. My dissertation consists of three essays examining the influence of contextual factors on the patterns of knowledge-sourcing of firms. I argue that both the geographical location and the institutional framework exert an influence in the way firms search for innovative knowledge outside of their own boundaries and across geographical distances. The first essay focuses on the geographical aspect and explores the influence of location in a peripheral region on the patterns of collaboration for innovation. The second essay focuses on the institutional aspect, exploring the effect of specific public policies on the characteristics of innovation practices. The third essay combines both aspects and studies the changes in the patterns of innovation, both in terms of technological breadth and geographical footprint, after a change of ownership produced by the privatization of formerly state-owned companies.

\section{Essay 1: The Geographical Dispersion of Inventor Networks in Peripheral Economies}

The first essay focuses on the influence of geographical factors (in particular the location in a peripheral economy) on patterns of knowledge sourcing. The concept of a "peripheral" economy fills an intermediate category (Molero, 1995) in the rigid "developed vs. developing/ emerging" economies dichotomy. Peripheral economies are techni- cally considered developed but lack certain characteristics of the "core" regions of Europe in terms of innovation and economic activity, such as level of interdependence, levels of foreign investment and MNE activity, shallow knowledge pools, and low innovative activity (Benito \& Narula, 2008, Narula \& Guimón, 2010). While the literature about these peripheral economies is growing, little is known about the patterns of innovation activity and international connectivity in these settings. Fine-slicing and international dispersion of global value networks provides opportunities for non-core locations to participate in the high knowledge components of global value chains. Further, since peripheral economies are likely to lag the core in terms of innovation capabilities in almost all sectors, connectivity is likely to have particularly strong effects for them.

Using patent data, I examine the dispersion of inventor networks in two countries located in the periphery of Europe: Portugal and Greece. I find that in these settings, the disaggregation of innovation across national borders will depend on a combination of location, multinationality of the firm, knowledge tacitness, and organizational capabilities in innovation. With respect to location, inventors in core areas tend to be connected to more dispersed innovation networks than inventors in peripheral areas. Consistent with theory, when inventors are engaged in tacit knowledge creation, their innovative activities tend to be co-located. However, when the orchestrator of the innovation is a highly innovative company, innovation involving tacit knowledge tends to be more geographically dispersed than in less innovative companies, confirming empirically (for the first time) the propositions of Cantwell and Santangelo $(1999,2000)$.

\section{Essay 2: Public Support for Innovation and the Openness of Firms" Innovation Activities}

The second essay explores whether publicly-funded schemes for innovation are related to an increase in the "openness" of firms' innovation practices. This piece of work combines two streams of research that had not been connected before. The first is the literature on open innovation (Chesbrough, 2006), and the second is the literature on the effects of public support for innovation. The overarching motivation of this paper is to shed light on how schemes to support innovation at the macro level, whether through direct monetary support (e.g., subsidies for innovation, financing for new projects, tax breaks for R\&D) 
or non-monetary support (e.g., information, facilitation of collaboration), can affect firms' micro level innovation activities. At the macro level, governments design schemes to foster innovation in general. At the micro level, firms pursue innovation in order to gain a competitive advantage; those who engage in open innovation activities can improve their innovative performance, but they also need to commit resources to build and manage these collaborative relationships. It follows that, if public support plays a role in supplying part of those resources, firms can potentially undertake more open innovation, which in turn can have a positive effect on their aggregated innovation production. There is a clear connection between these macro and micro levels of analysis, but in spite of its topical relevance for both managers and governments, prior research has paid limited attention to this potentially relevant area of inquiry.

The empirical analysis is based on survey data from more than 5,000 firms in 29 countries. I find that both monetary and non-monetary support policies for innovation are related to an increase in the degree of openness of individual firms. This openness is expressed both in terms of the number of external partners with whom they collaborate (from none to a maximum of four types of partners) and the number of open innovation activities they perform (from none to a maximum of seven types of open innovation activities). However, the relationship between the extent of public support and openness seems to be negatively moderated by the existence of previous innovative activity within the firm. Public support has more impact on less innovative firms and less influence when the firm is already innovative, which implies that it is important to target such supports in order to maximize their impact. Additionally, I find that non-monetary support is more critical than financial support in increasing openness. For policymakers facing salient financial constraints, this implies that institutions and government policies can play an important role in fostering open innovation.

Other interesting conclusions can be drawn from the empirical results. Internal innovation and innovation expenditures are related to a larger number of open innovation activities, but not so clearly to a larger number of partners. This implies that firms that innovate more internally also tend to have more open innovation activities, but not necessarily more external partners. This may be due in part to the fact that the firms that have the most powerful incentive to build ties with external partners are those that have an internal weakness as innovators; they may be the ones that seek external collaborations to compensate for their shallow knowledge foundation. The relationship with internal search scope (i.e., the number of functional areas involved in the innovation process) is positive and significant in all models, indicating that firms that search broadly for internal knowledge tend to be more open as well. This suggests that some of the capabilities needed to search internally across different areas of the company to manage cross-functional integration (Love \& Roper, 2009), are also enablers of open innovation. As expected, firm size is a positive determinant of openness, but only for activities and not for partners. However, multinationals seem to be more likely to work with external partners, but not necessarily to undertake more open innovation activities. Newer firms appear to be more open in terms of partnerships than older firms; this may be explained by the need new firms have to search externally for partners that can provide the knowledge they haven't been able to generate internally yet. Finally, the role of contextual factors shows some interesting results. I find that intellectual property (IP) doesn't have a significant relationship with openness, meaning that policies that ensure high protection of IP rights do not necessarily encourage more openness. This is counterintuitive, since one of the risks of being open is to lose secrets and knowledge to potential competitors; therefore, logically more protection of IP rights should encourage greater knowledge sharing. A possible explanation is that in these more mature institutional environments, firms have greater absorptive capacity and hence greater ability to absorb competitors' knowledge, so firms in general may be more protective. It has been documented that, in weak institutional environments, firms may conduct significant innovation and still protect themselves from the loss of knowledge through alternative mechanisms. In terms of national levels of innovation, R\&D intensity is positive and significant, consistent with the notion that a context of high-innovation activity will provide more opportunities for collaboration.

\section{Essay 3: The Effect of Privatization on the Charac- teristics of Innovation}

The third essay explores the patterns of knowledge sourcing of firms before and after privatization. Privatization of state-owned enterprises generates the adoption of new management practices and changes in the companies' objectives. While the literature has abundantly explored the consequences of privatization over different aspects of firm performance (Boubakri \& Cosset, 1998, Megginson, Nash, \& Van Randenborgh, 1994), its effects on innovation have been scarcely explored. While some studies suggest that privatization produces a subsequent reduction in the amount of $R \& D$ investment, little else is known about specific changes in the patterns of innovation of privatized firms. The importance of exploring the effects of privatization on innovation is that more efficient innovation management may be an overlooked driver of performance in privatized firms. We know that concentration of ownership, hard budget constraints, focus on value maximization and better hiring practices tend to increase performance in privatized firms vis-à-vis state-owned ones. We know nothing, however, about the role innovation management plays in this context.

I used patent data from a set of privatized firms to compare the innovative activity before and after privatization. In order to compare the change in innovation patterns before vs. after privatization, I analyzed it in two ways. The first one is a direct comparison between all the patents filed before the privatization date vs. the patents filed after. There are at least two potential issues with this approach. The first one is that patent filings are the result of a relatively long previous $R \& D$ process, which may take years to complete. This means that patents filed sometime after the privatization date may be reflecting innovation efforts that took place before the privatization. The second issue is that firms that 
are to be privatized sometimes change their management practices before the privatization, because governments make a deliberate effort to restructure the companies to make them more attractive to potential buyers. This means that patents filed a short time before or after the privatization may potentially be misleading indicators. For this reason I created two windows of three years each one, one starting five years (1825 days) before privatization and ending two years (730 days) before it. For comparison, I created a similar window after the privatization which starts 730 days after the privatization date and finishes 1825 (5 years) after it. This eliminates the potential issues with patents filed near the privatization date and provides with two comparable windows of equal length, but obviously reduces the sample size.

I find that privatized firms tend to focus on a narrower set of technologies as a response to increased pressure for profitability and short-term results. This is an important result that highlights the more efficient use of technology portfolios in privatized firms. I also analyze the competing arguments regarding the privatized firms' willingness to engage in collaborations with other firms and to disperse their innovation activities internationally. I find that collaboration and geographic dispersion of knowledge sourcing may be dependent on firm-specific factors, increasing in some cases after privatization, but not uniformly. What this study shows, overall, is that privatized firms show different patterns of knowledge sourcing and knowledge creation before and after the privatization event. This is a first but important exploratory step toward a more fine-grained understanding of the relationship between privatization and innovation practices, in order to complete the list of pillars that sustain the performance of privatized firms.

\section{Concluding Remarks}

This dissertation is an attempt to tap into the broad question of the relationship between a firm and its context. There are many areas to explore and many mechanisms still unknown that future research should unveil. My goal is to underline the solid motivations to pursue this line of inquiry. The main one is the importance of the implications for a broad array of stakeholders. First, for managers and firms, understanding the role of location and the effect of institutional frameworks and public policies is fundamental to make the right location decisions, to search for places that offer comparative advantages, and to design the best ways to orchestrate knowledge sourcing across multiple locations. For governments, more effective public policies and better allocation of resources for economic development will result in more innovative and dynamic economies, ultimately fostering job creation and growth. Last but not least, for academics, this intersection of distinct research strands offers a rich field full of uncharted questions with plenty of real-world implications. The door is now open.

\section{References}

Benito, G., \& Narula, R. 2008. States and firms on the periphery: The challenges of a globalising world. In G. Benito \& R.Narula (Eds), Multinationals on the periphery. London: Palgrave.

Boubakri, N., \& Cosset, J. C. 1998. The financial and operating performance of newly privatized firms: Evidence from developing countries. The Journal of Finance, 53(3): 1081-1110.

Cano-Kollmann, M., Cantwell, J., Hannigan, T. J., Mudambi, R., \& Song, J. 2016. Knowledge connectivity: An agenda for innovation research in international business. Journal of International Business Studies, 47(3): 255-262.

Cantwell, J., \& Santangelo, G. D. 1999. The frontier of international technology networks: sourcing abroad the most highly tacit capabilities. Information Economics and Policy, 11(1): 101-23.

Cantwell, J., \& Santangelo, G. D. 2000. Capitalism, profits and innovation in the new techno-economic paradigm. Journal of Evolutionary Economics, 10(1/2): 131.

Chesbrough, H. W. 2006. Open business models: How to thrive in the new innovation landscape. Boston: Harvard Business Press.

Love, J., \& Roper, S. 2009. Organizing innovation: Complementarities between cross-functional teams. Technovation, 29(3): 192-203.

Megginson, W. L., Nash, R. C., \& Van Randenborgh, M. 1994. The financial and operating performance of newly privatized firms: An international empirical analysis. Journal of Finance: 403-452.

Molero, J. (Ed.). 1995. Technological innovations, multinational corporations and the new international competitiveness: The case of intermediate countries. London: Harwood Academic Publishers.

Narula, R., \& Guimón, J. 2010. The R\&D activity of multinational enterprises in peripheral economies: Evidence from the EU new member states: UNU-MERIT, Maastricht Economic and Social Research and Training Centre on Innovation and Technology.

Marcelo Cano-Kollmann (canokoll@ohio.edu) is an Assistant Professor of Strategy and International Business at the Ohio University College of Business. He earned his Ph.D. from Temple University. His research is interdisciplinary in nature, lying at the intersection of international business, economic geography and innovation. Before entering academia, he worked in different positions in accounting, finance and general management, both in Argentina and the United States. 